\title{
Increased Carotid Intima-Media Thickness in Female Patients With Fibromyalgia: A Preliminary Study
}

\author{
Hüma BÖLÜK, Gökhan Tuna ÖZTÜRK, Didem CÖMERT, Murat ERSÖZ \\ Department of Physical Medicine and Rehabilitation, \\ Ankara Physical Medicine and Rehabilitation Training and Research Hospital, Ankara, Turkey
}

\begin{abstract}
Objectives: This study aims to measure the carotid artery intima-media thickness (IMT) of patients with fibromyalgia (FM) by using ultrasound imaging and to investigate whether carotid IMT measurements were associated with the severity of FM.

Patients and methods: Nineteen female patients (mean age $42.9 \pm 8.1$ years; range 24 to 57 years) and 17 healthy female subjects (mean age $41.5 \pm 6.3$ years; range 33 to 57 years) were included in this study. The Fibromyalgia Impact Questionnaire was used to determine the severity of FM. After clinical evaluation of the subjects, ultrasound imaging examinations of the carotid IMT were performed.

Results: Right and left carotid IMT values were thicker in the patient group in comparison to the control group ( $p_{1}=0.05$, $p_{2}=0.03$, respectively). Carotid IMT values were correlated with age and body mass index. Carotid IMT values did not have any correlation with blood glucose levels, creatinine levels, serum lipid profile and Fibromyalgia Impact Questionnaire scores in FM patients.

Conclusion: Carotid IMT of FM patients seems to be affected. Our finding may have stemmed from endothelial dysfunction possibly due to increased sympathetic activity.

Keywords: Carotid intima-media thickness; fibromyalgia; ultrasound.
\end{abstract}

Fibromyalgia $(\mathrm{FM})$ is a non-inflammatory rheumatologic syndrome characterized by chronic widespread pain as well as joint stiffness and systemic symptoms; i.e. fatigue, depression, cognitive dysfunctions, and sleep disturbances. ${ }^{1,2}$ The prevalence of FM is approximately $2 \%$ in the general population and is seven times more common in females than males. ${ }^{3}$ Although its etiopathogenesis has not yet been elucidated, various factors including genetic background, environmental stressors (i.e., psychosocial factors) and neuroendocrine system dysfunction have been suggested. ${ }^{2,4}$ Difficulty to fall asleep, chronic fatigue, headaches, bowel and bladder syndrome, paresthesia, anxiety and depression may be associated with FM. ${ }^{5}$ Additionally, sympathetic activity may increase in these patients due to pain and stress. ${ }^{6,7}$ Previous studies have shown that sympathetic overactivity and autonomic dysfunction may contribute to the risk of endothelial dysfunction and cardiovascular disease in patients with FM. ${ }^{2,8-12}$

Carotid intima-media thickness (IMT), a strong predictor of future vascular events, is used to detect early atherosclerosis. ${ }^{13,14}$ Ultrasonographic evaluations of carotid IMT correlate well with histological findings ${ }^{15}$ and increased IMT is related with cardiovascular events (i.e. angina pectoris and myocardial infarction). ${ }^{14,16}$ However, to the best knowledge of the authors, ultrasonographic assessment of the carotid IMT has not been performed in FM patients before.

Accordingly, in this study, we aimed to measure the carotid artery IMT of patients with FM by using ultrasound imaging and to investigate whether 
carotid IMT measurements were associated with the severity of FM.

\section{PATIENTS AND METHODS}

Nineteen female patients (mean age 42.9 \pm 8.1 years; range 24 to 57 years) who had been diagnosed with FM according to the 1990 American College of Rheumatology criteria ${ }^{1}$ and 17 healthy female subjects (mean age $41.5 \pm 6.3$ years; range 33 to 57 years) were enrolled as patient and control groups, respectively. Patients who had a history of any systemic disease (e.g. diabetes mellitus, thyroid abnormalities), rheumatologic disease (e.g. rheumatoid arthritis, systemic lupus erythematosus), or cardiovascular diseases were excluded. All subjects were informed about the study procedure and they consented to participate. The study protocol was approved by the local ethics committee.

Demographic and clinical characteristics of the patients including age, weight, height, body mass index, blood glucose and creatinine levels, and serum lipid profile were recorded. The Fibromyalgia Impact Questionnaire was used to determine the severity of FM. Fibromyalgia Impact Questionnaire consists of three main domains; function, overall impact, and symptoms. ${ }^{17}$ All of these domains are rated as numeric scales (0-10), and higher numbers reflect greater severity of the disease. ${ }^{17}$

Ultrasonographic measurements of carotid IMT were performed bilaterally by using a linear probe (7-12 MHz Logiq P5, B-mode, GE Medical Systems, Wisconsin, USA) by an experienced radiologist as described elsewhere. ${ }^{18}$ Right and left carotid IMT values of the subjects were recorded separately.

\section{Statistical analysis}

Statistical analysis was performed by using SPSS version 16.0 for Windows (SPSS Inc., Chicago, IL, USA) software program. Data are expressed as mean \pm standard deviation. Normal distribution of the data was shown by Kolmogorov-Smirnov test. Comparisons between patients and control subjects were performed with Student's t-test. Correlations among demographic/clinical characteristics and carotid IMT values were evaluated by Pearson rank coefficients. A $p$ value $\leq 0.05$ was considered as significant.

\section{RESULTS}

Clinical characteristics of the subjects are given in Table 1. Age, body mass index, blood glucose and creatinine levels, serum lipid profile were not different between the groups. Right and left carotid IMT values of the patient group were thicker than those of the control group ( $\mathrm{p}_{1}=0.05, \mathrm{p}_{2}=0.03$, respectively). Age and body mass index were correlated with right $\left(r_{1}=0.636, r_{2}=0.505\right.$, respectively) and left $\left(r_{1}=0.641, r_{2}=0.488\right.$, respectively) carotid IMT values in the patient group. In the control group, only age was correlated with right $(\mathrm{r}=0.608)$ and left $(r=0.665)$ carotid IMT values. Carotid IMT values did not have any correlation with blood glucose levels, creatinine levels, serum lipid profile and Fibromyalgia Impact Questionnaire scores.

Table 1. Clinical characteristics of subjects

\begin{tabular}{|c|c|c|c|}
\hline \multirow[t]{2}{*}{ Characteristic } & \multirow{2}{*}{$\frac{\text { Patients }(\mathrm{n}=19)}{\text { Mean } \pm \mathrm{SD}}$} & \multirow{2}{*}{$\frac{\text { Controls }(\mathrm{n}=17)}{\text { Mean } \pm \mathrm{SD}}$} & \multirow[b]{2}{*}{$p$} \\
\hline & & & \\
\hline Age (years) & $42.9 \pm 8.1$ & $41.5 \pm 6.3$ & 0.563 \\
\hline Body mass index $\left(\mathrm{kg} / \mathrm{m}^{2}\right)$ & $26.5 \pm 3.8$ & $24.9 \pm 4.2$ & 0.263 \\
\hline Right carotid intima-media thickness (mm) & $0.58 \pm 0.13$ & $0.50 \pm 0.10$ & 0.050 \\
\hline Left carotid intima-media thickness (mm) & $0.60 \pm 0.15$ & $0.50 \pm 0.11$ & 0.028 \\
\hline Glucose (mg/dL) & $95.6 \pm 11.3$ & $90.9 \pm 10.3$ & 0.203 \\
\hline Creatinine (mg/dL) & $0.61 \pm 0.12$ & $0.65 \pm 0.13$ & 0.370 \\
\hline Total cholesterol (mg/dL) & $194.8 \pm 32.8$ & $184.3 \pm 28.3$ & 0.345 \\
\hline Low density lipoprotein cholesterol (mg/dL) & $120.1 \pm 20.6$ & $120.4 \pm 23.1$ & 0.966 \\
\hline High density lipoprotein cholesterol (mg/dL) & $53.1 \pm 14.6$ & $46.1 \pm 10.8$ & 0.117 \\
\hline Fibromyalgia Impact Questionnaire scores & $62.9 \pm 11.6$ & - & - \\
\hline
\end{tabular}




\section{DISCUSSION}

In this study, we aimed to investigate whether carotid IMT were affected in patients with FM; and our results have shown that both carotid artery IMT values were thicker in the patients when compared with those of the healthy controls.

Fibromyalgia is characterized by chronic musculoskeletal pain, fatigue, sleep disturbance, cognitive dysfunction, and depression., ${ }^{1,2}$ In these patients, stress and pain may increase sympathetic nervous system (SNS) activity, and it has been reported that SNS function is changed in patients with FM..$^{6,7,12}$ On the other hand, arterial wall-stiffening process is significantly affected by SNS activity. ${ }^{12}$ Increased sympathetic activity may change cardiovascular responses and cause endothelial damage. Various mechanisms of endothelial dysfunction accompanying SNS activation have been suggested. ${ }^{19}$ It has been proposed that elevated levels of catecholamines play an important role in the pathophysiology of this disorder. ${ }^{20}$ Consistent activation of calcium channels, membrane damage, and microvascular spasm may be responsible for the mechanisms of catecholamine-induced endothelial dysfunction. ${ }^{21}$ In another hypothesis, autonomic nervous system dysfunction may lead to atherosclerosis. ${ }^{22}$ Sympathetic overactivity disrupts the autonomic nervous system control of the cardiovascular system and contribute to the development of endothelial damage and atherosclerosis. ${ }^{23}$ Overall, increased risk of endothelial dysfunction and atherosclerosis in patients with FM may thus be inevitable, and FM is associated with coronary heart disease. ${ }^{24}$ Likewise, in a study, it has been reported that FM was associated with cardiovascular morbidity. ${ }^{9}$ Additionally, increased serum lipids and markers of early atherosclerosis (mean platelet volume, asymmetric dimethylarginine) levels have been shown. ${ }^{2,8,25}$ Also, carotid IMT is an indicator of early atherosclerosis, and a powerful predictor of cardiovascular disease. ${ }^{13,14}$ It is widely used in rheumatologic diseases for evaluating the risk of cardiovascular disease..$^{13,26}$ Our results have shown that carotid IMT was thicker in patients with FM, and to the best knowledge of the authors, this result was the first demonstrated in the literature.

Carotid IMT values were used in other rheumatologic diseases (i.e. rheumatoid arthritis and systemic lupus erythematosus) to predict the risk of cardiovascular disease. ${ }^{18,26,27}$ Additionally, it has been showed that carotid IMT values were associated with clinical features of rheumatoid arthritis (i.e. long disease duration, degenerations, high inflammatory parameters, and extra-articular manifestations). ${ }^{28}$ However, in this study, carotid IMT values were not associated with disease severity in FM patients.

This study has some limitations; firstly, it was performed in females, since male FM patients have well known underlying factors on endothelial dysfunction and atherosclerosis (i.e. old age, smoking, dyslipidemia). In a study, carotid IMT values were higher in male healthy subjects than females; ${ }^{29}$ however, in this study, effects of sex on carotid IMT values in patients with FM were not evaluated. Secondly, the disease duration was not considered since newly diagnosed patients were included. Additionally, although decreased physical activity levels and increased sympathetic activity are important risk factors for cardiovascular diseases in FM patients, they were not evaluated in this study. Nevertheless, our results were considerable and noteworthy.

Thus, in light of our findings, we may conclude that carotid IMT values seem to be affected (thicker) in patients with FM. Our first and preliminary results need to be confirmed in future studies, possibly with further longitudinal assessment with regard to the development of cardiovascular disease in these patients.

\section{Declaration of conflicting interests}

The authors declared no conflicts of interest with respect to the authorship and/or publication of this article.

\section{Funding}

The authors received no financial support for the research and/or authorship of this article.

\section{REFERENCES}

1. Wolfe $\mathrm{F}$, Smythe HA, Yunus MB, Bennett RM, Bombardier C, Goldenberg DL, et al. The American College of Rheumatology 1990 Criteria for the Classification of Fibromyalgia. Report of the Multicenter Criteria Committee. Arthritis Rheum 1990;33:160-72.

2. Ünübol AȘ, Bozbağ GT, Ünübol M, Gürer G. An evaluation of mean platelet volume and serum lipid 
profile in patients with fibromyalgia syndrome. Arch Rheumatol 2013;28:251-5.

3. Wolfe F, Ross K, Anderson J, Russell IJ, Hebert L. The prevalence and characteristics of fibromyalgia in the general population. Arthritis Rheum 1995;38:19-28.

4. Bradley LA. Pathophysiology of fibromyalgia. Am J Med 2009;122:22-30.

5. McCarberg B, Barkin RL, Wright JA, Cronan TA, Groessl E, Schmidt SM. Tender points as predictors of distress and the pharmacologic management of fibromyalgia syndrome. Am J Ther 2003;10:176-92.

6. Giske L, Vøllestad NK, Mengshoel AM, Jensen J, Knardahl S, Røe C. Attenuated adrenergic responses to exercise in women with fibromyalgia--a controlled study. Eur J Pain 2008;12:351-60.

7. Martinez-Lavin M. Biology and therapy of fibromyalgia. Stress, the stress response system, and fibromyalgia. Arthritis Res Ther 2007;9:216.

8. Haliloğlu S, Carlioglu A, Sahiner E, Karaaslan Y, Kosar A. Mean platelet volume in patients with fibromyalgia. Z Rheumatol 2014;73:742-5.

9. Inal S, İnal EE, Okyay GU, Öztürk GT, Öneç K, Güz G. Fibromyalgia and nondipper circadian blood pressure variability. J Clin Rheumatol 2014;20:422-6.

10. Martínez-Lavín M, Hermosillo AG, Rosas M, Soto ME. Circadian studies of autonomic nervous balance in patients with fibromyalgia: a heart rate variability analysis. Arthritis Rheum 1998;41:1966-71.

11. Cohen H, Neumann L, Shore M, Amir M, Cassuto Y, Buskila D. Autonomic dysfunction in patients with fibromyalgia: application of power spectral analysis of heart rate variability. Semin Arthritis Rheum 2000;29:217-27.

12. Lee JH, Cho KI, Kim SM, Lee HG, Kim TI. Arterial stiffness in female patients with fibromyalgia and its relationship to chronic emotional and physical stress. Korean Circ J 2011;41:596-602.

13. Karaoğlan B, Öztürk GT, Özdoğan V, Cumaoğlu A, Oktar S, Tass $\mathrm{N}$, et al. Investigation of the correlation between ADMA levels and carotid artery intima-media thickness in rheumatoid arthritis patients. Turk $\mathrm{J}$ Phys Med Rehab 2011;57:114-8.

14. Lorenz MW, Markus HS, Bots ML, Rosvall M, Sitzer M. Prediction of clinical cardiovascular events with carotid intima-media thickness: a systematic review and meta-analysis. Circulation 2007;115:459-67.

15. Pignoli P, Tremoli E, Poli A, Oreste P, Paoletti $\mathrm{R}$. Intimal plus medial thickness of the arterial wall: a direct measurement with ultrasound imaging. Circulation 1986;74:1399-406.

16. Rosvall M, Janzon L, Berglund G, Engström G, Hedblad B. Incident coronary events and case fatality in relation to common carotid intima-media thickness. $\mathrm{J}$ Intern Med 2005;257:430-7.

17. Williams DA, Arnold LM. Measures of fibromyalgia: Fibromyalgia Impact Questionnaire (FIQ), Brief Pain Inventory (BPI), Multidimensional Fatigue Inventory
(MFI-20), Medical Outcomes Study (MOS) Sleep Scale, and Multiple Ability Self-Report Questionnaire (MASQ). Arthritis Care Res (Hoboken) 2011;63:86-97.

18. Tutoğlu A, Boyaci A, Boyaci N, Kaya Z, Aridici R, Koca I. Is There Any Relationship between Joint Destruction and Carotid Intima-media Thickness in Patients with Rheumatoid Arthritis? J Phys Ther Sci 2014;26:1093-6.

19. Cho KI, Lee JH, Kim SM, Lee HG, Kim TI. Assessment of endothelial function in patients with fibromyalgia--cardiac ultrasound study. Clin Rheumatol 2011;30:647-54.

20. Wittstein IS, Thiemann DR, Lima JA, Baughman KL, Schulman SP, Gerstenblith G, et al. Neurohumoral features of myocardial stunning due to sudden emotional stress. N Engl J Med 2005;352:539-48.

21. Zaroff JG, Rordorf GA, Titus JS, Newell JB, Nowak NJ, Torchiana DF, et al. Regional myocardial perfusion after experimental subarachnoid hemorrhage. Stroke 2000;31:1136-43.

22. Marwah RS, Doux JD, Lee PY, Yun AJ. Is atherosclerosis a neurogenic phenomenon? Med Hypotheses 2007;69:884-7.

23. Dekker JM, Crow RS, Folsom AR, Hannan PJ, Liao $\mathrm{D}$, Swenne $\mathrm{CA}$, et al. Low heart rate variability in a 2-minute rhythm strip predicts risk of coronary heart disease and mortality from several causes: the ARIC Study. Atherosclerosis Risk In Communities. Circulation 2000;102:1239-44.

24. Tsai PS, Fan YC, Huang CJ. Fibromyalgia is associated with coronary heart disease: a population-based cohort study. Reg Anesth Pain Med 2015;40:37-42.

25. Topal G, Donmez A, Doğan BS, Kucur M, Cengiz DT, Berkoz FB, et al. Asymmetric dimethylarginine (ADMA) levels are increased in patients with fibromyalgia: correlation with tumor necrosis factor- $\alpha$ (TNF- $\alpha$ ) and 8-iso-prostaglandin F(2 $\alpha)$ (8-iso-PGF $(2 \alpha)$ ). Clin Biochem 2011;44:364-7.

26. Mohan A, Sada S, Kumar BS, Sarma KV, Devi BV, Rao PV, et al. Subclinical atherosclerosis in patients with rheumatoid arthritis by utilizing carotid intimamedia thickness as a surrogate marker. Indian $\mathrm{J}$ Med Res 2014;140:379-86.

27. Leonard D, Akhter T, Nordmark G, Rönnblom L, Naessen $T$. Increased carotid intima thickness and decreased media thickness in premenopausal women with systemic lupus erythematosus: an investigation by non-invasive high-frequency ultrasound. Scand J Rheumatol 2011;40:279-82.

28. Targonska-Stepniak B, Drelich-Zbroja A, Majdan M. The relationship between carotid intima-media thickness and the activity of rheumatoid arthritis. J Clin Rheumatol 2011;17:249-55.

29. Mazurek K, Zmijewski P, Czajkowska A, Lutoslawska G. Gender differences in carotid artery intima-media thickness and flow-mediated dilatation in young, physically active adults. J Sports Med Phys Fitness 2014;54:298-306. 